\title{
Urologic Issues During Pregnancy
}

\author{
Jeffrey P. Weiss, MD, FACS \\ Clinical Adjunct Assistant Professor of Urology, New York Hospital-Cornell Medical Center \\ E-mails: Urojock@aol.com \\ Previously published in the Digital Urology Journal
}

Pregnancy induces a variety of physiologic changes in the urinary tract. When such changes become accentuated the physiologic becomes the pathologic and symptoms arise, at times of significance enough to threaten the well being of mother and/or fetus. This article intends to describe the basis for urinary physiology and its pathologic counterparts during pregnancy. Such a background may then facilitate a rational management protocol for various urologic problems in the gravid state.

KEYWORDS: Pregnancy, physiology, hydronephrosis, calculi, infection, renal failure, transplantation

DOMAIN: urology

\section{URINARY TRACT SYMPTOMS DURING PREGNANCY}

Frequency of voiding and stress incontinence are the most common urinary symptoms experienced by the gravid patient. Additional symptoms include urinary urgency, urge incontinence, incomplete emptying, and slow stream $(1,2)$. Hematuria is a physiologic change of pregnancy owing to microanatomic alterations in venous fragility of the collecting tubules (3). Flank pain may be due to accompanying processes such as calculi, hydronephrosis, pyelonephritis or spontaneous renal rupture, a phenomenon peculiar to pregnancy.

\section{Pregnancy-Induced Changes in Renal Physiology}

Hydroureteronephrosis is the most significant renal functional alteration of pregnancy, accounted for by both hormonal and mechanical factors. Increases in circulating estrogenic, progestational and prostaglandin-like agents are known to cause ureterectasis in the absence of obstruction during pregnancy $(4,5)$. Stasis caused by dextrorotation of the expanding uterus is the principal mechanical factor leading to hydroureteronephrosis of pregnancy and explains its tendency to occur on the right.

Glomerular filtration rate (GFR) and renal plasma flow (RPF) are ordinarily increased during pregnancy (6). Both of these changes are attributable to increases in cardiac output, decreases in renal vascular resistance and increases in serum levels of progesterone, aldosterone, deoxycorticosterone, placental lactogen and chorionic gonadotropin (7). Increased urinary excretion of glucose, amino acids, protein and vitamins are consequent to increases in RPF and GFR $(8,9)$. 
Renal volume is seen to increase during pregnancy up to $30 \%$ normal size, a result of increased RPF and glomerular surface area under the influence of prolactin and its growth hormone-type of effect (10). In addition, we see hypercalciuria as a concomitant of pregnancy due to increased GFR, calcium filtration and intestinal calcium absorption related to high levels of plasma calcitriol $(11,12)$. However, an increase in inhibitors of stone-formation such as citrate, magnesium and glycosaminoglycans yields the result that pregnancy is unassociated with a net change in rates of stone formation $(13,14)$.

While increases in GFR of pregnancy would ordinarily cause the loss of 5,000 to 10,000 mEq sodium daily (15), there are mitigating factors resulting in maintenance of sodium homeostasis among which are tubular reabsorption (16), and increases in mineralocorticoid-like compounds such as aldosterone (17), deoxycorticosterone (18), estrogens (19), ACTH, prolactin, cortisol, growth hormone and placental lactogen (20). The influence of the renin-angiotensin axis upon sodium homeostasis is mediated by aldosterone metabolism and volume status (21). Physical factors affecting sodium regulation during pregnancy are increases in ureteral pressure and uterine blood supply. Thus, the net effect of the multiple aforementioned factors upon sodium metabolism is a slight sodium retention in pregnant subjects.

\section{HYDRONEPHROSIS OF PREGNANCY}

Gestational upper urinary tract dilatation results from evolution of a physiologic process, namely, ureteral compression by the expanding uterus (22). Because hydroureteronephrosis of pregnancy occurs as an outcome of dextrorotation of the uterus at mid-term, it usually happens on the right $(23,24)$. Ureterectasis is also thought to have a non-obstructive component, related to hormonal changes induced by a functioning placenta $(25,26)$.

Painful hydronephrosis of pregnancy is conventionally treated by having the patient remain situated to the left in order to relieve ureteral pressure induced by the dextrorotated uterus (fig 1a, 1b). When this measure fails, ureteral stenting or establishment of percutaneous drainage are effective in pain relief and preventing evolution of hydronephrosis to spontaneous renal rupture (28-32). Alternative resolutions to the problem of symptomatic gestational hydronephrosis include induction of labor and delivery $(33,34)$, and epidural block (35).

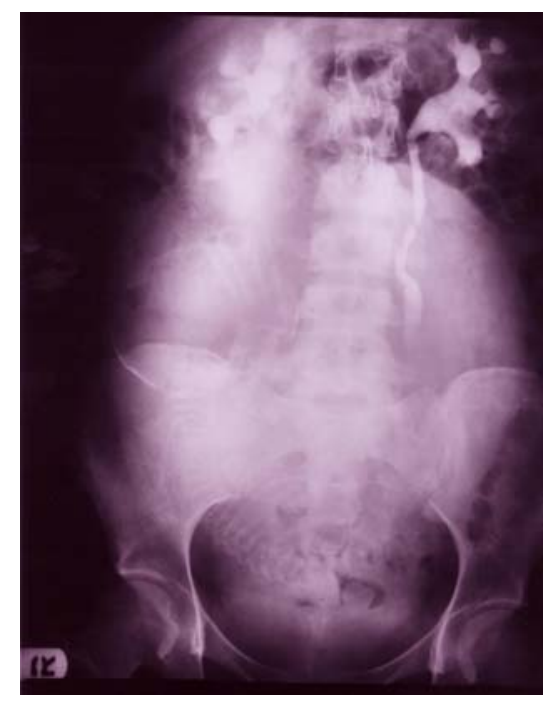

FIGURE 1a. Urogram, third trimester patient complaining of right flank pain, 15 minute film demonstrates bilateral hydronephrosis. 


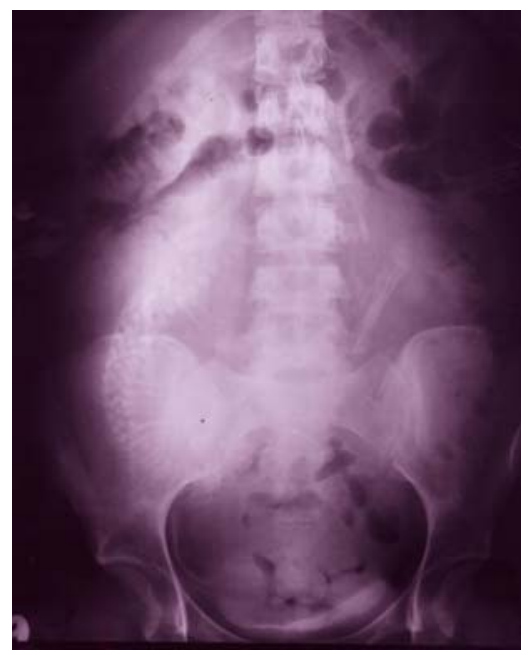

FIGURE 1b. Same patient, 2.5 hour film demonstrates near-total drainage of all contrast. Diagnosis: Symptomatic right hydronephrosis of pregnancy, moderate without evidence true obstruction. Pain resolved with bedrest in the left contralateral position.

Spontaneous renal rupture (SRR) is a potentially fatal complication of unchecked gestational obstructive uropathy, thought to be occasioned by increased hydrostatic pressure leading to extravasation from overstressed calyceal-renal capsular junctions (36). A recent review of non-traumatic rupture of the gravid urinary tract reveals that it is uncommon, with 25 reported cases to 1995 (27). The majority of cases occurred in diseased kidneys, typically harboring tumors. About half the renal units ruptured through the collecting system and half through parenchyma. Also at risk are renal units rendered less than normally compliant due to prior infection, surgery or trauma. While SRR occurs between 18 weeks of pregnancy and 1 day post-parturition (37), this phenomenon is accompanied by symptoms of loin pain, hematuria, flank mass and hypotension. Diagnosis is made through the use of ultrasound, excretory urography and retrograde studies. Arteriography may be both diagnostic (in identification of the vessel or vessels responsible for hypotension) and therapeutic in such instances (angioembolization), though relatively contraindicated in the first trimester because of high radiation dosages necessary in most cases (38).

\section{DECISION-MAKING FOR GESTATIONAL URINARY TRACT IMAGING}

Significant pelvic radiation dosages (5-15 cGy) during the first trimester increase the risk of teratogenicity from 1 to 3 percent (39). Putting this into perspective, a standard urogram renders 1.5 cGy to the fetus; however, prudence dictates the standard that limited exposure to 2 or 3 Îshotsâ should be taken during a gestational urogram. These images include the plain film, a thirty minute exposure and 2-3 hour exposure if the diagnosis of obstruction remains in doubt. Since each plain abdominal film yields 0.2 cGy to the fetus, the 2 or 3 shot urogram is considered safe even during the first trimester (40-42). On the other hand, data exists to cause concern with even low doses of roentgen ray exposure to the fetus. Specifically, an average of 1 rad of fetal exposure has been correlated with a net 2.4-fold increase in the incidence of all childhood malignancies (43). However, it is not clear during which trimesters radiation exposure occurred. While ultrasound is safe under all circumstances of pregnancy, its utilization in diagnosing obstruction is of limited value owing to its suboptimal view of the ureter and presence of hydroureteronephrosis as a physiologic concomitant of pregnancy. Thus, because urography is found to have diagnostic value greatly in excess of sonography during pregnancy (44), it is recommended in the following situations: [a] persistent fever [b] massive or increasing hydronephrosis as seen during serial 
urosonography [c] pain and or emesis refractory to conservative therapy. The theoretical risk of development of childhood cancer (not necessarily teratogenicity) should at all times be kept in mind when subjecting the fetus to roentgen ray exposure $(45,46)$. In particular, there is no evidence that fetal radiation exposure below 5 rad causes congenital malformation, spontaneous abortion or growth retardation (47). However, the relative risk of childhood leukemia occasioned by fetal exposure of 1-2 rad is increased from 1/3000 (general population) to 1/2000 (48). Put into perspective, the risk of leukemia for a sibling of a leukemic child is 1/700 (49).

In view of these data, it is useful to discuss radiation dosages received by the uterus owing to specific imaging studies. For example, cerebral angiography causes less than 10 mrad exposure to the uterus, a negligible dosage, due to the maximum distance of the collimated beam from the brain to the pelvis (50). In contrast, double vessel coronary angioplasty provides 90 mrad uterine exposure $(51,52)$ and barium enema causes 2-4 rad fetal exposure due to proximity of the study to the uterus (53). Other roentgen ray studies may be ordered during pregnancy. Computed tomography causes maximum radiation exposure at the skin level with a progressive decrease toward the body interior. Correspondingly, radiation dosage to the fetus diminishes with enlargement of the pregnancy and its investing tissues (54). Specifically, a 10 slice abdominal study causes 2.6 rad fetal exposure at weeks 0 - 14 whereas the same study provides only 1.7 rad to the conceptus at weeks 35-42 (55-57). Likewise, administration of radiopharmaceuticals may be safely done during pregnancy. Nuclear medicine studies of the brain, biliary system, skeleton, lungs, kidneys, abscesses and heart may all be accomplished with fetal exposures varying from 40 to 1100 mrad (58). In general, because radioactive iodine readily crosses the blood-placental barrier, isotopic iodine administration should be avoided during pregnancy (59). Magnetic imaging is felt to be safe during pregnancy in that studies of static, gradient and radiofrequency magnetic fields at strengths lower than 2 tesla have thus far failed to demonstrate mutagenic or other deleterious effects upon the fetus (60-63).

In summary,it is useful to keep in mind the American College of Obstetricians and Gynecologists' guidelines for diagnostic imaging during pregnancy (64):

- Counseling that $\mathrm{x}$-ray exposure under 5 rad has not been associated with increased in fetal anomaly or spontaneous abortion.

- Maternal health should not be compromised by irrational fears of the dangers of ionizing radiation to the fetus. However, alternative imaging procedures such as ultrasonography and magnetic resonance imaging should be employed instead of x-rays where applicable.

- While ultrasonography and magnetic resonance imaging are unassociated with known adverse fetal effects, magnetic resonance imaging to date is not recommended for use in the first trimester.

- Radiologic consultation is advisable if it is deemed necessary to estimate fetal dose when roentgenologic procedures are performed during pregnancy.

- Therapeutic radioactive iodine isotopes are contraindicated during pregnancy.

\section{URINARY CALCULOUS DISEASE DURING PREGNANCY}

Because factors which tend to increase stone formation are balanced by inhibitory influences during pregnancy, pregnant patients are no more likely to manufacture urinary calculi than their nonpregnant counterparts. Specifically, decreased ureteral peristalsis, hydronephrosis, infection and calcium supersaturation all enhance the stone-forming propensity in pregnancy, whereas augmented excretion of stone inhibitors such as citrate, magnesium and glycosaminoglycans tend to neutralize the former stoneenhancing factors $(65,66)$.

As in all other patients, calculous disease of pregnancy is accompanied by symptoms of flank or abdominal pain, nausea, vomiting and lower urinary urgency. Because most calculi during pregnancy are located in the ureter, sonography will usually be insufficient to make the diagnosis. Thus, in accordance 
with the above discussion, roentgenographic imaging studies are necessary to diagnose many symptomatic gestational urinary tract calculi.

The primary treatment of stones in pregnant subjects is expectant, as most will pass spontaneously (67-71). Refractory cases will be treated with ureteral stenting with monthly stent changes due to the proclivity for calcific encrustation during pregnancy (72). Ureteroscopy (with or without laser lithotripsy) is facilitated by the compliant ureter of pregnancy and is helpful in resolving the problem of obstruction and pain without the need for morbid long-term stenting in these patients (73-76). My personal preference for ureteroscopy done without $\mathrm{x}$-ray exposure is to cystoscopically pass a guidewire into the distal ureter which is usually straight even during the third trimester. Over this wire a 7 french steerable ureteroscope may be advanced under direct vision into the kidney at which time the wire may be placed confidently into the kidney. The calculus may then be basketed or destroyed with laser or electrohydraulic lithotripsy. The stent may be advanced through the cystoscope until a single pigtail remains in the bladder. If doubt exists a single ( $0.2 \mathrm{rad})$ plain film can confirm stent position. While stenting has been reported to be effective in the majority of cases (77), a large (6 or 7 french) stent should be used, as one series demonstrated relief of obstruction in the gravid ureter in less than $50 \%$ of cases (78).

Percutaneous nephrostomy and open lithotomy in selected circumstances continue to be legitimate options for treatment of gestational urinary calculi (79-81). On the other hand, the status of extracorporeal shock wave lithotripsy is unclear: despite the fact that female fertility is thought to be unchanged by ESWL (82), the lack of data pertaining to safety of shock waves upon the developing fetus renders pregnancy a relative contraindication to ESWL.

\section{URINARY RECONSTRUCTION AND PREGNANCY}

Pregnancy is possible in patients having undergone prior urinary tract reconstruction, whether for neurogenic bladder, tumor or voiding dysfunction. Fenn et al (83) described 19 pregnancies in 18 women aged 21 to 36 years having undergone clam enterocystoplasty for intractable detrusor instability. Pajor et al (84) advocate lower urinary reconstruction with an ileocecal as opposed to ileal bowel segment in order to avoid uterine-induced mesenteric compromise during the course of pregnancy. Kennedy et al (85) reported upon successful pregnancies in 4 women with exstrophy having had flap vaginoplasty and creation of subsequent continent right colonic urinary reservoir with an orthotopic perineal stoma (Indiana pouch). The authors performed cesarian section and close monitoring for maternal or fetal distress in all cases. Creagh et al (86) reported 34 pregnancies in 27 women with reconstructed lower urinary tracts who underwent either vaginal or cesarian delivery, indicated by specific obstetrical considerations. The majority of their patients (28/34) in fact underwent successful vaginal delivery. Thus, patients having undergone lower urinary reconstruction may safely deliver either vaginally or via C-section; attendance of the urologist is essential in all cases.

\section{URINARY TRACT INFECTION IN PREGNANCY}

Twenty to forty percent of pregnant women with asymptomatic bacteruria during the first trimester will become afflicted with pyelonephritis in the third trimester $(87,88)$. In addition, eradication of bacteruria diminishes the incidence of pyelonephritis and its attendant associations with prematurity, growth retardation and low birth weight $(89,90)$. Thus, it is considered axiomatic that asymptomatic bacteruria should be screened for, treated and then prophylaxed (91). As is the case for nonpregnant patients, a clean catch urine culture yielding greater than 100,000 colony forming units per cc is considered significant for purposes of treatment and antibiotic prophylaxis for the remainder of the duration of pregnancy (92). Screening for and treatment of asymptomatic bacteruria to prevent third trimester pyelonephritis has been demonstrated to be cost-effective with either culture or dipstick strategies in comparison to a no-screening policy (93). Urethritis due to Chlamydia trachomatis occurs in $50 \%$ of women with dysuria, pyuria and urinary frequency (94). In addition, chlamydial cervicitis was found in $21 \%$ of 11,544 women at their first 
prenatal visit, and untreated was associated with premature rupture of membranes as well as low birth weight and decreased survival (95). Neonatal complications of chlamydial infection included nasopharyngitis, pneumonitis and conjunctivitis. Thus, chlamydia is not 'normal flora' and should be treated when discovered during pregnancy with erythromycin $500 \mathrm{mg}$ four times daily for seven to ten days (96). Screening of the lower genital tract in pre-termination patients has been advocated to reduce the $63 \%$ incidence of pelvic inflammatory disease in patients harboring both chlamydia and anaerobic vaginosis (97).

The bacteriology of urinary infection in pregnancy involves gram negative rods, notably, E. coli, Klebsiella/Enterobacter, Proteus, as well as gram positive cocci and enterococci (98). While pregnancy per se does not statistically affect susceptibility to urinary infection, diabetics are colonized more frequently with group B streptococcus (although the latter agent does not account for increased infection rate in the diabetic pregnant population) $(99,100)$. An interesting aspect of pregnancy is a relative status of immunosuppression, presumably due to the presence of the "foreign" genome of the fetus. Petersson et al (101) reported significant decline in the immune response in pregnant subjects to acute pyelonephritis. That is, maternal serum and urine interleukin-6 and specific antibody responses to E. coli were diminished in comparison to the situation in their non-pregnant counterparts at diagnosis.

Treatment of bacteruria (whether symptomatic or not) of pregnancy entails initial eradication of the offending microorganism followed by establishment of a program of uroprophylaxis. Initial treatment ranges from single dose to three day to ten day courses of antibiotics known to be free of teratogenic side effects (102-105). A randomized, controlled study of patients with pyelonephritis of pregnancy demonstrated the adequacy of outpatient treatment using a 10 day course of oral cephalexin (106). Subsequent prophylaxis may take the form of the same uropharmaceutical administered as a single nightly dose throughout pregnancy or merely as a postcoital dose (107). Urinary bacteriologic studies should then be maintained routinely, for example, monthly during gestation. Positive cultures despite prophylaxis are then responded to in the same fashion as the initial positive culture. Antibiotics thought safe during pregnancy (barring allergy) are: penicillins, cephalosporins and erythromycin. Others may be safely used with certain caveats: nitrofurantoin (watch for hemolysis in breastfed infants with G-6-PD deficiency), aminoglycosides (monitor levels) and sulfonamides (cause hemolysis/kernicterus after 28 weeks if G-6-PD deficiency exists). All other antibiotics are either contraindicated or carry strong relative contraindications during pregnancy (108). Table 1 provides a comprehensive description of antibiotic use during pregnancy.

\section{LOWER URINARY DYSFUNCTION IN PREGNANCY}

Urinary stress incontinence and frequency constitute the major lower tract symptoms attributable to the gravid state; in contrast, retention during pregnancy occurs uncommonly $(109,110)$. Because retention is related to bladder neck obstruction caused by uterine retroversion and posterior movement of the cervix (especially in the first trimester), treatment entails manual repositioning of the fundus or placement of a pessary $(111,112)$.

Stress incontinence of pregnancy occurs as a result of myogenic and/or neurogenic damage to the urethral sphincter especially following dystocia or forceps delivery (113). This Îdirect traumaâ theory is complemented by an alternate mechanism, namely, intrinsic change in urethral smooth muscle function induced by pregnancy itself, rather than birth trauma. Such a concept is supported by data revealing that patients with stress incontinence exhibit progressive diminution in urethral closure pressure as pregnancy progresses as opposed to their pregnant but continent counterparts whose urethral length and closure pressures increase toward term $(114,115)$. A hormonal etiology for pregnancy-induced stress incontinence has also been proposed, specifically, urethral collagen depolymerization and softening mediated by the corpus luteum hormone Relaxin (116). Recent experimental data supports the concept that pregnancy induces alteration of smooth muscle compliance and functional responses of the bladder neck and urethra to various forms of autonomic stimulation and relaxation occasioned by the profound hormonal changes which are part and parcel of the gravid endocrine milieu (117). 
TABLE 1

Antibiotic use in pregnancy

\begin{tabular}{ll}
\hline Antibiotic & \multicolumn{1}{c}{ Safety margin (barring allergy) } \\
\hline penicillins & safe \\
cephalosporins & safe \\
erythromycin & safe \\
nitrofurantoin & safe (hemolytic anemia in breastfed infants with G-6-PD deficiency) \\
aminoglycosides & safe: monitor serum levels/renal function \\
sulfonamides & safe until 28 weeks (thereafter risk hemolysis/kernicterus if G-6-PD deficiency) \\
trimethoprim & contraindicated in first trimester (teratogenic, fetal folate antagonist) \\
tetracyclines & contraindicated (fetal limb/dental dysgenesis) \\
chloramphenicol & contraindicated near term (fetal bone marrow depression, "gray syndrome") \\
isoniazid & causes congenital defects: infant encephalopathy \\
metronidazole & use with caution second/third trimesters only (?mutagenic) \\
amox/clavulanate & formal studies lacking \\
quinolones & contraindicated due to effects on fetal bone and cartilage \\
ketoconazole & contraindicated (teratogenic in rats; inhibits steroid synthesis) \\
\hline
\end{tabular}

A related issue is pregnancy in patients having been previously treated for stress incontinence, whether due to urethral hypermobility or intrinsic sphincter deficiency. While those having undergone retropubic suspension or sling procedures may deliver without jeopardizing the repair via cesarian section $(118,119)$, vaginal delivery may ensue without ill effect upon prior implantation of either periurethral collagen or the artificial urinary sphincter $(120,121)$.

\section{PREGNANCY AND RENAL FAILURE}

Acute and chronic renal failure are caused and exacerbated, respectively, by pregnancy. Related issues deal with the effects of pregnancy upon the patient with established renal failure treated with either dialysis or transplantation.

Acute renal failure of pregnancy is subcategorized etiologically into three groups: prerenal, renal and postrenal. Hypovolemia due to hyperemesis gravidarum and uterine hemorrhage are the principle underlying causes of prerenal azotemia of pregnancy (122). Hemorrhage in turn is caused by abortion, placenta previa and abruption. Failure to replenish appropriate volume components causes prerenal azotemia to evolve into acute tubular necrosis (ATN), the most frequent etiology of gestational ARF (the other significant etiology being renal cortical necrosis [RCN]). RCN results from disseminated intravascular coagulation (DIC, in the setting of amniotic fluid embolism, intrauterine fetal demise or abruption), transfusion reactions and sepsis (chorioamnionitis, septic abortion and pyelonephritis) (123125). RCN and ATN differ in that the former is manifested by anuria and irreversible renal impairment followed by renal cortical calcification in the healing phase, whereas the latter infrequently presents with anuria and tends to resolve to satisfactory renal function (126).

Pregnancy may or may not adversely affect kidney function in patients with established chronic renal failure (CRF). For example, 35\% of patients with serum creatinines greater than $1.6 \mathrm{mg} / \mathrm{dl}$ in one series developed rapid renal deterioration (127). Likewise, reflux nephropathy tends to be aggravated by 
pregnancy: eight of 20 patients with this condition developed endstage renal disease (ESRD) within two years of delivery or abortion (128). Jungers et al concluded that while pregnancy may proceed uneventfully in patients with established reflux nephropathy but normal blood pressure and serum creatinine, there is compromise in both fetal prognosis and maternal renal function if pregnancy progresses in the presence of azotemia (129). Mansfield et al found that patients having undergone vesicoureteral reimplantation as children were at higher than normal risk for intragravid urinary infection, but suffered no increase in the incidence of spontaneous abortion (130). Belman (131) recommends warning women with a history of childhood urinary infection that they are both at risk for bacteruria of pregnancy and require antibiotic prophylaxis regardless of the state of their reflux during pregnancy. On the other hand, patients with autosomal dominant polycystic kidney disease may be counseled that their renal function is unlikely to be altered by pregnancy (132).

Despite the potentially deleterious effects of pregnancy upon renal function in patients with established CRF, pregnancy is indeed a possibility in patients with ESRD on dialysis. While offspring of such patients have no increased likelihood of congenital anomalies, they tend toward low birth weights. Mothers with ESRD tend to experience worsening of both hypertension and residual renal function $(133,134)$.

Whereas renal transplantation increases the chance for pregnancy from 1/200 (dialysis patient) to 1/50 (135), transplanted kidneys tend not (85\% of cases) to suffer ill effects from the processes of gestation, labor and delivery $(136,137)$. It is recommended that renal transplant patients seeking childbearing become pregnant two to five years following transplantation since pregnancy more than five years after transplantation resulted in a $75 \%$ incidence of serious renal injury, while the pregnancy itself fared better more than two years post-transplantation $(138,139)$.

\section{URINARY TRACT TUMORS DISCOVERED DURING PREGNANCY}

Despite pregnancy being an immunologically impaired state, the incidence of malignancy is similar to that in the general population (140). A wide variety of urologic tumors has been reported to occur during pregnancy (141). Specifically, renal cell carcinoma is the commonest renal neoplasm of pregnancy; since the latter is a condition of the young, angiomyolipoma occurs next in frequency (142). For the same reason, Wilms tumor is known in pregnancy (143). Bladder cancer during pregnancy may take the form of adenocarcinoma (144), transitional cell carcinoma $(145,156)$ or squamous cell lesions (147). As electrical current may induce neighboring uterine contractions, obstetrical treatment to diminish uterine smooth muscle reactivity may be helpful in reducing the possibility of premature labor from electroresection and cautery. Similarly, laser phototherapy is useful to treat bladder tumors of pregnancy while eschewing prematurity.

Adrenal tumors such as pseudocyst $(148)$ and pheochromocytoma $(149,150)$ are extant during pregnancy. Key issues in pheochromocytoma of pregnancy include diagnostic conundra (symptoms and signs resemble those of preeclampsia leading to more than 50\% mortality when undiagnosed); choice of alpha blockade (prazosin, to avoid teratogenicity of phenoxybenzamine); means of imaging (magnetic resonance imaging is especially useful for localizing pheochromocytoma and is free of ionizing radiation); timing of surgical resection (expeditiously); and route of delivery (vaginal preferred) (151156).

\section{TIMING OF ANESTHESIA DURING PREGNANCY}

General anesthesia in and of itself does not entail a risk of adversity to pregnancy (157). This holds especially true when the (nonobstetric) procedure is complication-free. A landmark study from Scandinavia evaluated 5405 incidental surgical procedures performed during all 3 trimesters of pregnancy. While the incidence of low birthweight and prematurity was greater in these patients as compared with a large cohort of pregnancies, there was no tendency toward congenital malformation in 
the operated group. It was concluded that there is an increased risk of prematurity following intragravid surgical procedures requiring general anesthesia which may be attributed to the underlying condition rather than the procedure or anesthetic itself $(158,159)$.

Other considerations involving anesthesia during pregnancy include timing of semiurgent procedures which may not be postponed until parturition. There is evidence that nonobstetric surgical procedures are most safely performed during the second trimester owing to the increased risk of spontaneous abortion during the first trimester and induction of premature labor when procedures take place near term (160).

A related issue is the diminished requirement for both local and general anesthetics during pregnancy (161). Thus, dosages of inhalational anesthetics such as halothane and isoflurane should be reduced in pregnancy to compensate for the sedative effects of progesterone (162-164). Likewise, the requirement for local anesthetics is decreased during the first trimester due to increased cell membrane receptor sensitivity to these agents, again a progestational-mediated phenomenon $(165,166)$.

\section{CONCLUSION}

Urologic problems during pregnancy are often undertreated due to unfounded fears of causing fetal harm. An understanding of pathophysiologic changes in the urinary tract as well as appropriate use of antimicrobials, anesthetics, imaging studies and invasive procedures will lead to resolution of most such problems while providing a margin of safety for both mother and child.

\section{REFERENCES}

1. Stanton, S.L., Kerr-Wilson, R. and Grant Harris, V.: The incidence of urological symptoms in normal pregnancy, Br J Obstet Gynecol 87:897-900, 1980.

2. Cutner, A., Cardozo, L.D. and Benness, C.J.: Assessment of urinary symptoms in early pregnancy, Br J Obstet Gynaecol 98:1283-1286, 1991.

3. Waltzer, W.C.: The urinary tract in pregnancy, J Urol 125:271-276, 1981.

4. Van Wagenen,G., Newton, W.H.: Pregnancy in the monkey after removal of the fetus, Surg Gynec Obst 77:539, 1943.

5. Rasmussen, P.E., Nielsen, F.R.: Hydronephrosis during pregnancy: A literature survey, Eur J Obstet Gynecol Reprod Biol 27:249, 1988.

6. Dunlop, W., Davison, J.M.: Renal haemodynamics and tubular function in human pregnancy, Clin Obstet Gynaecol 1:769, 1987.

7. Lindheimer, M.D., Katz, AI: The kidney and hypertension in pregnancy. In Brenner BM, Rector FC, editors: The kidney vol II, Philadelphia, 1991, WB Saunders Co.

8. Wright, A., et al: The urinary excretion of albumin in normal pregnancy, Br J Obstet Gynaecol 94:408, 1987.

9. Boler, L., et al: Quantitation of proteinuria in pregnancy by the use of single voided urine samples, Obstet Gynec 70:99-100, 1987.

10. Christensen, T., et al: Changes in renal volume during normal pregnancy, Acta Obstet Gynecol Scand 68:541-543, 1989.

11. Gertner, J.M., et al: Pregnancy as state of physiologic absorptive hypercalciuria, Am J Med 81:451-456, 1986.

12. Marya, R.K. Rathee, S. and Manrow, M: Urinary calcium excretion in pregnancy, Gynecol Obstet Invest 23:141-144, 1987.

13. Gambaro, G., et al: Increased urinary excretion of glycosaminoglycans in pregnancy and in diabetes mellitus: A protective factor against nephrolithiasis, Nephron 50:62-63, 1988.

14. Bisaz, S., et al: Quantitative determinations of inhibitors of calcium phosphate precipitation in whole urine, Miner Electrol Metabol 1:74-83, 1978.

15. $\quad$ Lindheimer, M.D, Katz, Al.: The kidney vol II, 1991.

16. Baylis, C.: Glomerular filtration and volume regulation in gravid animal models, Clin Obstet Gynaecol 1:789, 1987.

17. Brown, M.A. et al: Potassium regulation and progesterone-aldosterone interrelationships in human pregnancy. A prospective study, Am J Obstet Gynecol 155:349, 1986.

18. Brown, R.D., Strott C.A. and Liddle, G.W.: Plasma deoxycorticosterone in normal and abnormal pregnancy, J Clin Endocrinol Metab 35:736, 1972.

19. Wilson, M., et al: Blood pressure, the renin-aldosterone system and sex steroids throughout normal pregnancy, Am J Med 68:97, 1980.

20. $\quad$ Lindheimer, M.D, Katz, Al.: the kidney vol II, 1991.

21. Hsueh, W.A., et al: Changes in active and inactive renin throughout pregnancy, J Clin Endocrinol Metab 54:1010, 1982. 
22. Harrow,B.R., Sloane, J.A and Salhanick, L.: Etiology of the hydronephrosis of pregnancy, Surg Gynecol Obstet 119:1042-1048, 1964.

23.

24.

25.

26.

27.

28.

29.

30.

31.

32.

33.

34.

35.

36.

37.

38.

39.

40.

41.

42.

43.

44.

45.

46.

47.

48.

49.

50.

51.

52.

53.

54.

55.

56.

57.

58.

Weiss, J.P., Hanno, PM: Pregnancy and the Urologist, AUA update series 9:266-271, 1990.

Eckford,S.D., Gingell, J.C.: Ureteric obstruction in pregnancy--diagnosis and management, Br J Obstet Gynaecol 98:1137-1140, 1991.

Van Wagenen, G., Newton, W.H.: Surg Gynec Obst 77:539, 1943.

Van Wagenen, G, Jenkins, R.H.: An experimental examination of factors causing ureteral dilatation of pregnancy, J Urol 42:1010, 1939.

Wolff, J.M., Jung, P.K., Adam, G. and Jakse, G.: Non-traumatic rupture of the urinary tract during pregnancy. Br.J. Urol. 76:645, 1995.

Eika, B., Skajaa, K.: Acute renal failure due to bilateral ureteral obstruction by the pregnant uterus, Urol Int 43:315317, 1988.

Stothers, L., Lee, L.M.: Renal colic in pregnancy, J Urol 148:1383-1387, 1992.

Nielsen, F.R., Rasmussen, P.E.: Hydronephrosis during pregnancy: four cases of hydronephrosis causing symptoms during pregnancy, Eur J Obstet Gynecol Reprod Biol 27:245-248, 1988.

VanSonnenberg, E., et al: Symptomatic renal obstruction or urosepsis
guided percutaneous nephrostomy, Am J Radiol 158:91-94, 1992.

Pryor, J.L., Gillenwater, J.Y.: A new technique for retrograde stone displacement in the tortuous ureter before extracorporeal shock wave lithotripsy, J Urol 142:778-779, 1989.

O'Shaughnessy, R.,Weprin, S.A. and Zuspan, F.R.: Obstructive renal failure by over distended pregnant uterus, Obstet Gynecol 55:247-249,1980.

D'Elia, F.L., Brennan, R.E. and Brownstein, P.K.: Acute renal failure secondary to ureteral obstruction by a gravid uterus, J Urol 128:803-804, 1982.

Ready, L.B., Johnson, E.S.: Epidural block for treatment of renal colic during pregnancy, Canad Anaesth Soc J 28:7779, 1981.

Meyers, S.J., Lee, R.V. and Munschauer, R,W.: Dilatation and nontraumatic rupture of the urinary tract during pregnancy: A review, Obstet Gynecol 66:809-815, 1985.

Meyers,S.J., Lee,R.V. and Munschauer,R.W.: Obstet Gynecol 66:809-815, 1985.

Izumoto, H. et al: Spontaneous renal rupture in pregnancy, Arch Surg 124:389, 1989.

Swartz, H.M., Reichling, B.A.: Hazards of radiation exposure for pregnant women, JAMA 239:1907-1909, 1978.

Maikranz, P., et al: Nephrolithiasis in pregnancy, Am J Kid Dis 9:354-358, 1987.

Horowitz, E., Schmidt, J.D.: Renal calculi in pregnancy, Clin Obstet Gynecol, 28:324-338, 1985.

Drago, J.R., Rohner, T.J. Jr. and Chez, R.A.: Management of urinary calculi in pregnancy, Urol 20:578-581, 1982.

Harvey, E.B., Boice, J.D. and Honeyman, M., et al: Prenatal x-ray exposure and childhood cancer in twins. N.E.J.M. 312:541, 1985.

Horowitz, E., Schmidt, J.D.: Clin Obstet Gynecol, 28:324-338, 1985.

MacMahon, B.: Prenatal X-ray exposure and childhood cancer. J.N.C.I. 28:1173, 1962.

Mole, R.H.: Antenatal irradiation and childhood cancer: Causation or coincidence? Br. J. Cancer 30:199, 1974.

Brent, R.L.: The effect of embryonic and fetal exposure to x-ray, microwaves and ultrasound: Counseling the pregnant and nonpregnant patient about these risks. Semin. Oncol. 16:347, 1989.

Shu, X.O., Jin, F., Lnet, M.S. and Zheng, W., Clemens, J., Mills, J. and Gao, Y.T.: Diagnostic X-ray and ultrasound exposure and risk of childhood cancer. Br. J. Cancer 70:531, 1994.

Brent, R.L.: Semin. Oncol. 16:347, 1989.

Wagner, L.K., Lester, R.G. and Saldana, L.R.: Exposure of the pregnant patient to diagnostic radiation. Philadelphia, Lippincott, pp 40-61, 1985.

1. Gorson, R.O., Lassen, M. and Rosenstein, M.:Patient dosimetry in diagnostic radiology. In: Handbook of Medical Physics, vol. II. Edited by Waggener, R.G., Kereiakes, J.G. and Shalek, R. Boca Raton, CRC Press, 1984.

Finci, L., Meier, B., Steffenino, G., Roy, P. and Rutishauser, W.: Radiation exposure during diagnostic catheterization and single- and double-vessel percutaneous transluminal coronary angioplasty. Am. J. Cardiol. 60:1401, 1987.

Bednarek, D.R., Rudin S., Wong, R. and Andres, M.L.: Reduction of fluoroscopic exposure for the air-contrast barium enema. Br. J. Radiol. 56:823, 1983.

4. Medical and Surgical Complications in Pregnancy. In: Williams Obstetrics. Edited by Cunningham, F.G., MacDonald, P.C., Gant, N.F., Leveno, K.J., Gilstrap, L.C., Hankins, G.D.V. and Clark, S.L. Stamford: Appleton \& Lange, section XIII, chapter 45, pp. 1045-1057, 1997.

5. Cunningham, F.G., MacDonald,P.C., Gant, N.F.,Leveno, K.J.,Gilstrap,L.C., Hankins, G.D.V. and Clark, S.L.: Section XIII, chapter 45, pp. 1045-1057, 1997.

6. Shope,T.G., Gagne, R.M. and Johnson, G.C.: A method for describing the doses delivered by transmission x-ray computed tomography. Med. Phys. 8:488, 1981.

7. Ragossino, M.W., Breckle, R., Hill, L.M. and Gray J.E.: Average fetal depth in utero: Data for estimation of fetal absorbed radiation dose. Radiology 158:513, 1986.

8. Cunningham, F.G., MacDonald, P.C., Gant,N.F., Leveno, K.J.,Gilstrap,L.C., Hankins, G.D.V. and Clark, S.L.: Section XIII, chapter 45, pp. 1045-1057, 1997. 
59. Wagner, L.K., Fabrikant, J.I. and Fry, R.J.M.: Radiation Bioeffects and Management Test and Syllabus. Reston, VA, American College of Radiology, 1991.

60. Cunningham, F.G., MacDonald, P.C., Gant,N.F., Leveno, K.J.,Gilstrap,L.C., Hankins, G.D.V. and Clark, S.L.:Section XIII, chapter 45, pp. 1045-1057, 1997.

61. Wagner, L.K., Lester, R.G. and Saldana, L.R.:Lippincot, pp 40-61, 1985.

62. Geard, C.R., Osmak, R.S., Hall, E.J., Simon, H.E., Maudsley, A.A. and Hilal, S.K.: Maganetic resonance imaging and ionizing radiation: A comparative evaluation in-vitro of oncogenic and genotoxic potential. Radiology 152:199, 1984.

63. Schwartz, J.L., Crooks, L.E.: NMR imaging produces no observable mutations or cytotoxicity in mammalian cells. Am. J. Radiol. 139:5, 1982.

64. American College of Obstetricians and Gynecologists: Guidelines for diagnostic imaging during pregnancy. Committee Opinion no. 158. September, 1995.

65. Gambaro, G., et al: 50:62-63, 1988.

66. Maikranz, P., et al: 9:354-358, 1987.

67. $\quad$ Stothers, L., Lee, L.M.:J Urol 148:1383-1387, 1982.

68. Lattanzi, D.R., Cook, W.A.: Urinary calculi in pregnancy, Obstet Gynecol 56:462-466, 1980.

69. Denstedt, J.D., Razvi, H.: Management of urinary calculi during pregnancy, J Urol 148:1072-1075, 1992.

70. Hendricks, S.K., Ross, S.O. and Krieger, J.N.: An algorithm for diagnosis and therapy of management and complications of urolithiasis during pregnancy, Surg Gynecol Obstet 172:49-54, 1991.

71. Loughlin, K.R., Bailey, R.B. Jr.: Internal ureteral stents for conservative management of ureteral calculi during pregnancy, N Engl J Med 315:1647-1649, 1986.

Rodriguez, P.N., Klein, A.S.: Management of urolithiasis during pregnancy, Surg Gynecol Obstet 166: 103-106, 1988.

Rittenberg,M.H., Bagley, D.H.: Ureteroscopic diagnosis and treatment of urinary calculi during pregnancy, Urol 32:427-428, 1988.

74. Carringer, M., Swartz, R. and Johansson, J.E.: Management of ureteric calculi during pregnancy by ureteroscopy and laser lithotripsy. Br. J. Urol. 77:17, 1996.

75. Scarpa, R.M., De Lisa, A. and Usai, E.: Diagnosis and treatment of ureteral calculi during pregnancy with rigid ureteroscopes. J. Urol. 155:875, 1996.

76. Ulvik, N.M., Bakke, A.. and Hoisaeter, P.A.: Ureteroscopy in pregnancy. J. Urol. 154:1660, 1995.

77. Zwergel, T., Lindenmeir, T. and Wullich B.: Management of acute hydronephrosis in pregnancy by ureteral stenting. Eur. Urol. 29:292, 1996.

78. Knebel, L., Tschada, R., Mickisch, G., Zieger, W. and Alken, P.: Le drainage interne de l'urine en cas de stase urinaire compliquee provoquee par une grossesse. Journal d'Urologie 99:169, 1993.

79. $\quad$ Drago, J.R., Rohner, T.J. Jr. and Chez, R.A.: Urol 20:578-581, 1982.

80. Harris, R.E., Dunnihoo, D.R.: The incidence and significance of urinary calculi in pregnancy, Am J Obstet Gynecol 99:237-241, 1967.

81. Cumming, D.C., Taylor, P.J.: Urologic and obstetric significance of urinary calculi in pregnancy, Obstet Gynecol 53:505-508, 1979.

82. Vieweg, J., et al: Female fertility following extracorporeal shock wave lithotripsy of distal ureteral calculi, J Urol 148:1007-1010, 1992.

83. Fenn, N., Barrington, J.W. and Stephenson, T.P.: Clam enterocystoplasty and pregnancy. Br. J. Urol. 75:85, 1995.

84. Pajor, L., Koiss I., Nagy, F., Kopa, Z. and Keszthelyi, A.: Bladder augmentation with detubularized intestinal segment. Int. Urol. Nephrol. 27:387, 1997.

85. Kennedy, W.A., Hensle, T.W., Reiley, E.A., Fox, H.E. and Haus, T.: Pregnancy after orthotopic continent urinary diversion. Surg. Gynecol. Obstet. 177:405, 1993.

86. Creagh, T.A., McInerney, P.D., Thomas, P.J. and Mundy, A.R.: Pregnancy after lower urinary tract reconstruction in women. J. Urol. 154:1323, 1995.

87. Kass, E.H. Asymptomatic infection of urinary tract, Trans Assoc Am Phys 69:56-63, 1956.

88. Kass, E.H.: The role of unsuspected infection in the etiology of prematurity, Clin Obstet Gynecol 16:134-152, 1973.

89. Kass, E.H.: The role of asymptomatic bacteriuria in the pathogenesis of pyelonephritis. In Quinn, E.L. Kass, E.H., editors: Biology of pyelonephritis, Boston, 1960, Little Brown.

90. Condie, A.P., et al: Complications of bacteriuria in pregnancy. In O'Grady, F., Brumfitt, E., editors: Urinary tract infection, London, 1968, Oxford University Press.

91. Weiss, J.P. and Gillenwater, J.Y.: management of Urologic Problems in Pregnancy in: Adult and Pediatric Urology, Gillenwater,J.Y., Grayhack, J.T., Howards, S.S. and Duckett, J.W., editors, Mosby-Year Book, pp 353-367, St. Louis, 1996.

92. Patterson, T.F., Andriole, V.T.: Bacteriuria in pregnancy, Infect Dis Clin N Am 1:807-822, 1987.

93. Rouse, D.J., Andrews, W.W., Goldenberg, R.L. and Owen, J.: Screening and treatment of asymptomatic bacteruria of pregnancy to prevent pyelonephritis: a cost-effectiveness and cost-benefit analysis. Obstet. Gynecol. 86:119, 1995.

94. Watts, D.H., Eschenbach, D.A.: Treatment of chlamydia, mycoplasma, and group B streptococcal infections, Clin Obstet Gynecol 31:435-452, 1988.

95. Ryan et al:, 1990.

96. Watts, D.H., Eschenbach, D.A.: Treatment of chlamydia, mycoplasma, and group B streptococcal infections, Clin 
Obstet Gynecol 31:435-452, 1998.

97. Blackwell, A.L., Thomas, P.D., Wareham, K. and Emery, S.J.: Health gains from screening for infection of the lower genital tract in women attending for termination of pregnancy. Lancet 24:342, 1993.

98. MacDonald, P., et al: Summary of a workshop on maternal genitourinary infections and the outcome of pregnancy, $\mathrm{J}$ Infect Dis 147:596, 1983.

99. Stenqvist, K., et al: Virulence factors in escherichia coli in urinary isolates from pregnant women, J Infect Dis 156:870-877, 1987.

100. Matorras,R, et al: Recto-vaginal colonization and urinary tract infection by group B streptococcus in the pregnant diabetic patient, Acta Obstet Gynecol Scand 67:617-620, 1988.

101. Petersson, C., Hedges, S., Stenqvist, K., Sandberg, T., Connell, H. and Svanborg, C.: Suppressed antibody and interleukin-6 responses to acute pyelonephritis in pregnancy. Kidney Int. 45:571, 1994.

102. Krieger, J.N.: Complications and treatment of urinary tract infections during pregnancy, Urol Clin N Am 13:685-693, 1986.

103. Jakobi, P., et al: Single-dose antimicrobial therapy in the treatment of asymptomatic bacteriuria in pregnancy, Am J Obstet Gynecol 156:1148-1152, 1987.

104. Gerstner, G.J., Muller, G., Nahler, G.: Amoxicillin in the treatment of asymptomatic baceriuria in pregnancy: A single-dose of $3 \mathrm{~g}$ amoxicillin versus a 4-day course of three doses 750mg amoxicillin, Gynecol Obstet Invest 27:8487, 1989.

105. Harris, R.E., Gilstrap, L.C. Pretty, A..: A single-dose antimicrobial therapy for asymptomatic bacteriuria during pregnancy, Obstet Gynecol 59:546-549, 1982.

106. Millar, L.K., Wing, D.A.., Paul, R.H. and Grimes, D.A.: Outpatient treatment of pyelonephritis in pregnancy: a randomized controlled trial. Obstet. Gynecol. 86:560, 1995.

107. Pfau, A., Sacks, T.G.: Effective prophylaxis for recurrent urinary tract infections during pregnancy, Clin Infect Dis 14:810-814, 1992.

108. Weiss, J.P. and Gillenwater, J.Y.: Mosby-Year Book, pp.353-367, 1996.

109. Stanton, S.L., Kerr-Wilson, R. and Grant, Harris V.: Br J Obstet Gynecol 87:897-900, 1980.

110. Hansen, J.H., Asmussen, M.: Acute urinary retention in first trimester of pregnancy, Acta Obstet Gynecol Scand 64:279-280, 1985.

111. Goldberg, K.A., Kwart, A.M.: Intermittent urinary retention in first trimester of pregnancy, Urol 17:270-271, 1981.

112. Silva, P.D., Berberich, W.: Retroverted impacted gravid uterus with acute urinary retention: Report of two cases and a review of the literature, Obstet Gynec 68:121-123, 1986.

113. Swash, M.: Childbirth and incontinence, Midwifery 4:13-18, 1988.

114. Iosif,S.: Stress incontinence during pregnancy and in puerperium, Int J Gynaecol Obstet 19:13-20, 1981.

115. Iosif, S., Ulmsten, U.I.: Comparative urodynamic studies of continent and stress incontinent women in pregnancy and in puerperium, Am J Obstet Gynecol 140:645-650, 1981.

116. Petros, P.E.P., Ulmsten, UI.: Pregnancy effects on the intravaginal sling operation, Acta Obstet Gynecol Scand 153:77-78, 1990.

117. Lee, J.G., Wein, A.J. and Levin R.M.: Effects of pregnancy on urethral and bladder neck function. Urology 42:747,1993.

118. Cutner, A., Cardozo, L.D. and Wise, B.G.: The effects of pregnancy on previous incontinence surgery. Case report. Br. J. Obst. Gynec., 98:1181, 1991.

119. Petros, P.E. and Ulmsten, U.I.: Pregnancy effects on the intravaginal sling operation. Acta Obst. Gynec. Scand., suppl., 153:77, 1990.

120. Carr, L.K. and Herschorn, S.: Periurethral collagen injection and pregnancy. J. Urol. 155:1037, 1996.

121. Fishman, I.J. and Scott, F.B.: Pregnancy in patients with the artificial urinary sphincter. J. Urol. 150(2 pt 1):340, 1993.

122. Knuppel, R.A., Montenegro, R. and O'Brien, W.F.: Acute renal failure in pregnancy, Clin Obstet Gynecol 28:288-297, 1985.

123. Weiss, J.P., Gillenwater,J.Y.: Mosby-Year Book, pp.353-367, 1996.

124. Knuppel, R.A., Montenegro, R. and OâBrien, W.F.:Clin Obstet Gynecol 28:288-297,1985.

125. Grunfeld, J.P., Pertuiset, N.: Acute renal failure in pregnancy, Am J Kid Dis 9:359-362, 1987.

126. Weiss, J.P., Hanno, P.M.:AUA update series 9:266-271, 1990.

127. Imbasciati, E., et al: Pregnancy in women with chronic renal failure, Am J Nephrol 6:193-198, 1986.

128. Becke, G.J., et al: Effect of pregnancy on moderate renal failure in reflux nephropathy, Br Med J 292:796-798, 1986.

129. Jungers, P., Houillier, P., Chaveau, D., Choukroun G., Moynot, A., Skhiri, H., Labrunie, M., Descamps-Latscha, B. and Griunfeld J.P.: Pregnancy in women with reflux nephropathy. Kidney Int. 50:593, 1996.

130. Mansfield, J.T., Snow, B.W., Cartwright, P.C. and Wadsworth, K.: Complications of pregnancy in women after childhood reimplantation for vesicoureteral reflux: An update with 25 years of followup. J. Urol. 154(2 pt 2)787, 1995.

131. Belman, A.B.: A perspective on vesicoureteral reflux. Urol. Clin. N. Am. 22:139, 1995.

132. Lashgari, M., Keene, M.E.: Pregnancy in women with adult polycystic kidney disease, Conn Med 50:374-376, 1986.

133. Confortini, P., et al: Full term pregnancy and successful delivery in a patient on chronic hemodialysis, Proc Eur Dial Transpl Assoc 18:74-78, 1971. 
134. Redrow,M., et al: Dialysis in the management of pregnant patients with renal insufficiency, Med 67:199-208, 1988.

135. Casciani, C.U., et al: Pregnancy in renal transplantation, Clin Exp Obstet Gynecol 11:136-140, 1984.

136. Davison, J.M.: Changes in renal function in early pregnancy in women with one kidney, Yale J Med Biol 51:347, 1978.

137. Sciarra, J.J., et al: Pregnancy following renal transplantation, Am J Obstet Gynec 123:411-425, 1975.

138. $\quad$ Casciani, C.U.,et al: Clin Exp Obstet Gynecol 11:136-140, 1984.

139. Davison, J.M., Lindheimer, M.D.: Pregnancy in renal transplant patients, J Reprod Med 27:613-621, 1982.

140. Nieminen, N., Remes, N.: Malignancy during pregnancy. Acta Obstet. Gynecol. Scand. 49:315, 1970.

141. Loughlin, K.R.: Management of urologic problems in the pregnant patient. AUA Update Series 16:10, 1997

142. Walker, J.L., Knight, E.L.: Renal cell carcinoma in pregnancy. Cancer 58:2343, 1986.

143. Bozeman, G., Bissada, N.K., Abboud,M.R. and Laver, J.: Adult Wilms' tumor: Prognostic and management considerations. Urology 45:1055, 1995.

144. FitzGerald, M.P., Hernandez, E., Hadley, C. and Karafin, L.: Bladder Adenocarcinoma During Pregnancy: A Case Report. J. Reprod. Med. 41:59, 1996.

145. Bendsen, J., Muller, E.K. and Povey, G.: Bladder tumor as apparent cause of vaginal bleeding in pregnancy. Acta Obstet Gynecol. Scand. 64:329, 1985.

146. Choate, J.W., Thiede, H.A. and Miller, H.C.: Carcinoma of the bladder in pregnancy: Report of three cases. Am. J. Obstet. Gynecol. 90:526, 1964.

147. Karim, M., Ammar, R. and Dadawy, S.: Carcinoma of the bladder with pregnancy. J. Egypt Med. Assoc. 51:1037, 1968.

148. Trauffer, P.M. and Malee, M.P.: Adrenal pseudocyst in pregnancy. A case report. J. Reprod. Med. 41:195, 1996.

149. Schenker, J.G. and Grant, M.: Pheochromocytoma and pregnancy: An updated appraisal. Aust. N.Z. J. Obstet. Gynaecol. 22:1, 1982.

150. Burgess, G.E. III.: Alpha blockade and surgical intervention of pheochromocytoma in pregnancy. Obstet. Gynecol. 53:266, 1978.

151. Loughlin, K.R.: AUA Update Series 16:10, 1997.

152. Burgess, G.E. III.: Obstet. Gynecol. 53:266, 1978.

153. Schenker, J.G. and Grant, M.: Obstet Gynecol. 22:1, 1982.

154. Manger, W.M., Gifford, R.W. and Hoffman, B.B.: Pheochromocytoma: A clinical and experimental overview. Curr. Prob. Cancer. 9:1, 1985.

155. Wagener, G.W., Van Rendborg, L.C. and Schaetzing, A.: Pheochromocytoma in pregnancy. A case report and review. S. Afr. J. Surg. 19:251, 1981.

156. Griffin, J., Brooks, N., Patricia, F.: Pheochromocytoma in pregnancy: Diagnosis and collaborative management. South. Med. J. 77:1325, 1984.

157. Cunningham, F.G., MacDonald, P.C., Gant, N.F., Leveno, K.J., Gilstrap, L.C., Hankins, G.D.V. and Clark, S.L.: Section XIII, chapter 45, pp. 1045-1057, 1997.

158. Mazze, R.I. and Kallen, B.: Reproductive outcome after anesthesia and operation during pregnancy: A registry study of 5405 cases. Obstet. Gynecol. 161:1178, 1989.

159. Cohen, S.E.: Nonobstetric surgery during pregnancy. In: Obstetric Anesthesia. Edited by: Chestnut, D.H. St. Louis: Mosby, p. 273, 1994.

160. Hull, L.M., Johnson, C.E.,and Lee, R.A.: Cholecystectomy in pregnancy. Obstet. Gynecol. 9:291, 1975.

161. Loughlin, K.R.: AUA Update Series 16:10, 1997.

162. Palahniuk, R.J., Shnider, S.M. and Eger, E.I.: Pregnancy decreases the requirements for inhaled anesthetic agents. Anesthesiology 41:82, 1974.

163. Merman, W.: "Progesterone" anesthesia in human subjects. J. Clin. Endocrinol. Metab. 14:1567, 1954.

164. Lyreras, S., Nyberg, F.and Linberg, B.: Cerebrospinal fluid activity of dynorphin-converting enzyme at term pregnancy. Obstet. Gynecol. 72:54, 1988.

165. Fagraeus, L., Urban, B.J. and Bromage, P.R.: Spread of epidural analgesia in early pregnancy. Anesthesiology 58:184, 1983.

166. Datta, S., Lambert, D.H. and Gregus, J.: Differential sensitivities of mammalian nerve fibers during pregnancy. Anesth-Analg. 62:1070, 1983.

\section{This article should be referenced as follows:}

Weiss, J.P. (2004) Urologic issues during pregnancy. TheScientificWorldJOURNAL 4 (S1), 364-376.

\section{Handling Editor:}

Anthony Atala, Principle Editor for Urology — a domain of TheScientificWorldJOURNAL. 


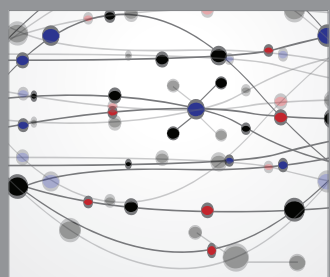

The Scientific World Journal
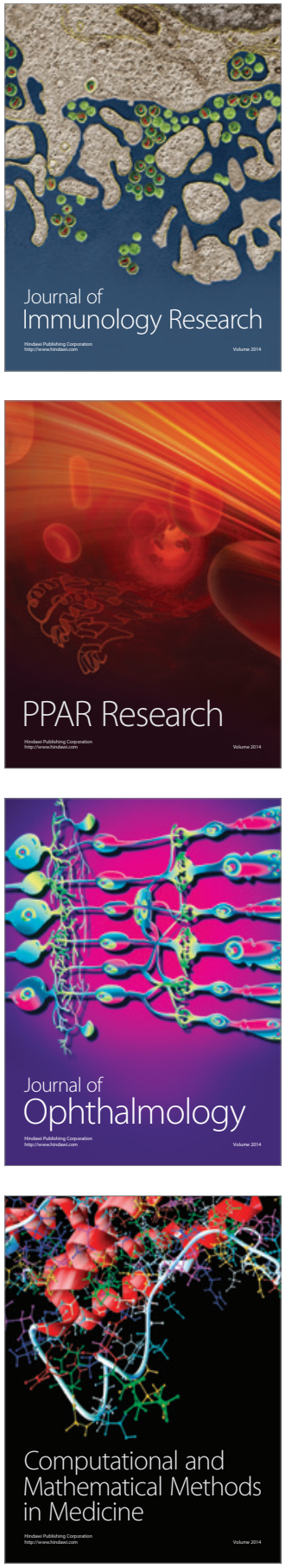

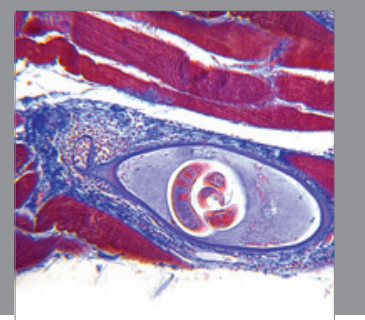

Gastroenterology

Research and Practice
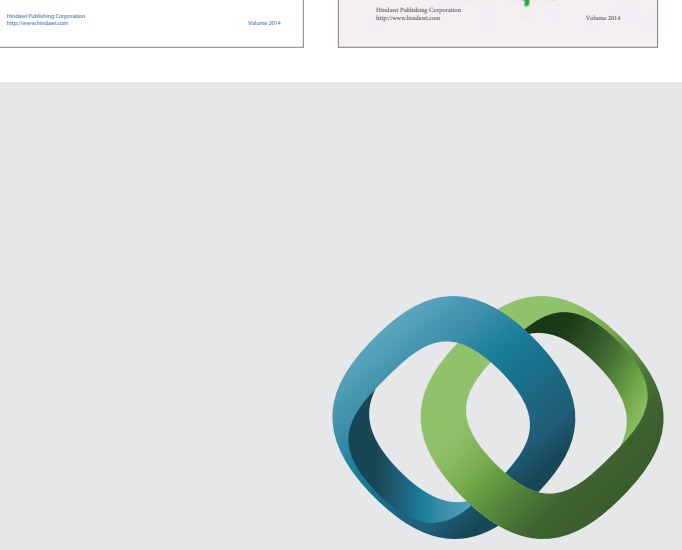

\section{Hindawi}

Submit your manuscripts at

http://www.hindawi.com
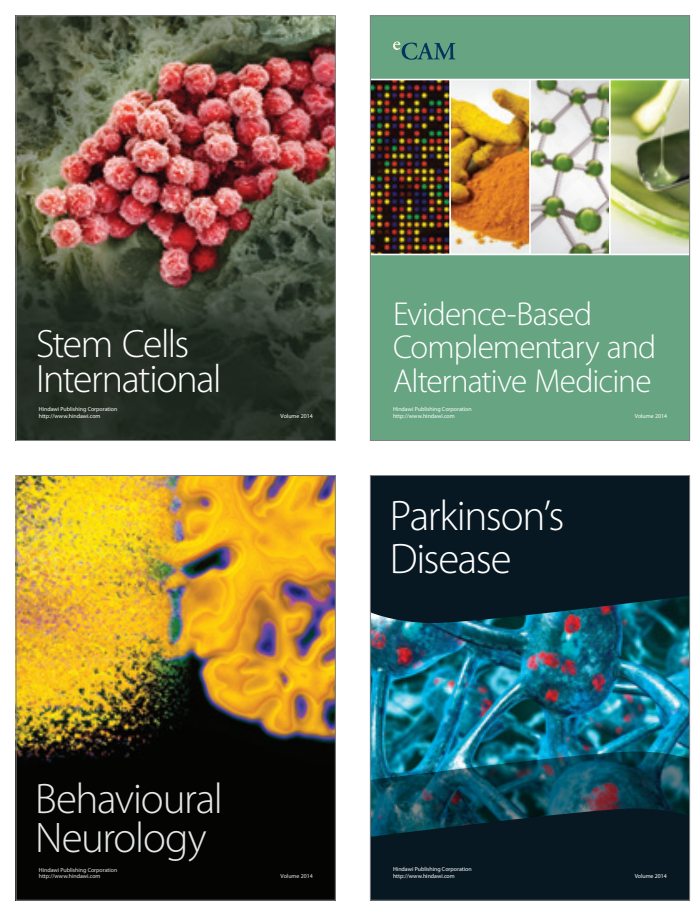

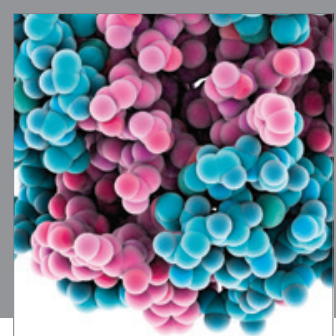

Journal of
Diabetes Research

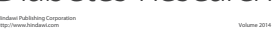

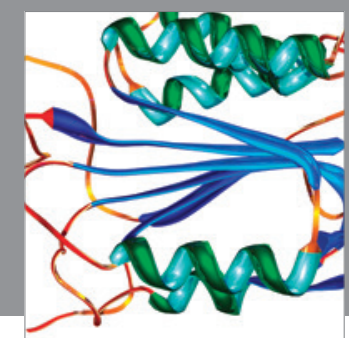

Disease Markers
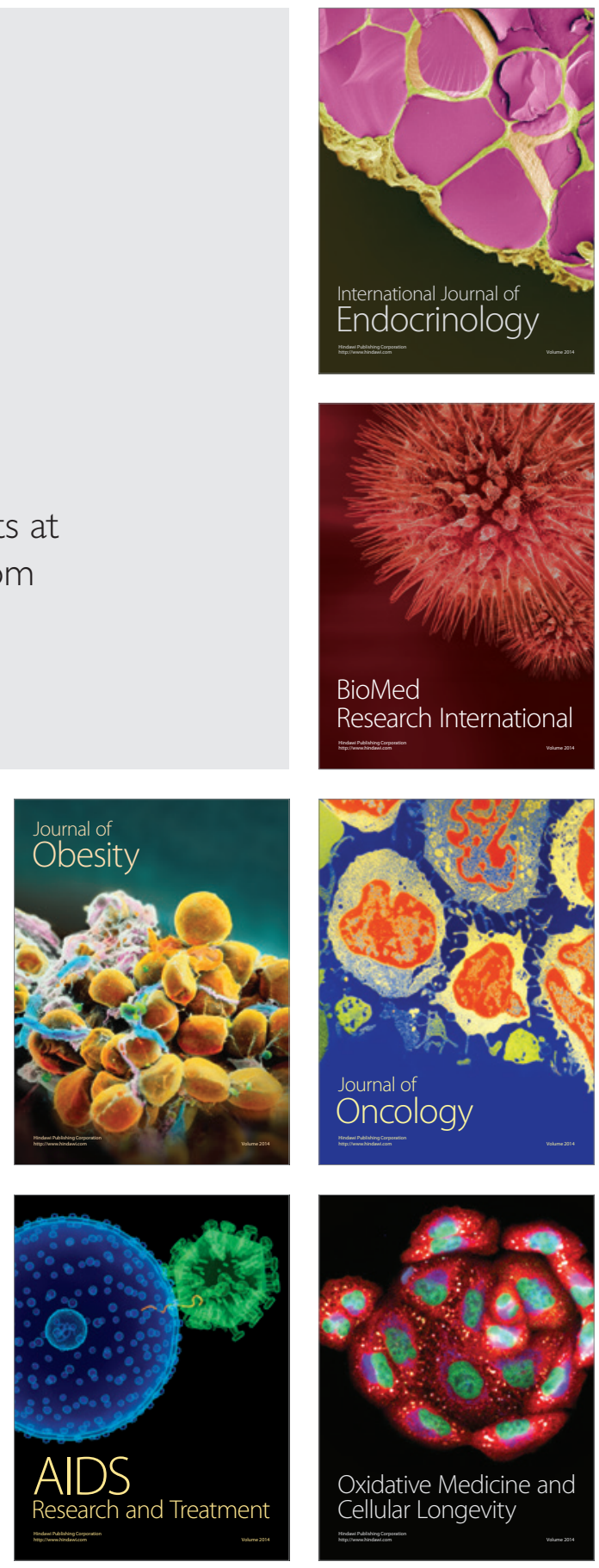